\title{
Fast Battery Charge Controller for Electrical Vehicle
}

\author{
Dinesh D. Gaikwad \\ Govt. Residence Women Poly \\ Manerajuri Road Tasgaon
}

\author{
Nikita P. Joshi \\ Govt. Residence Women Poly \\ Manerajuri Road Tasgaon
}

\author{
Pournima D. Gaikwad \\ VTC Patgaon \\ Miraj Pandharpur Road Miraj
}

\begin{abstract}
As the green technology increases in popularity, more and more electric vehicles (EVs) of all kinds from electric scooters to cars to buses and cargo trucks will grace the roads. Electronic designers will be challenged to provide systems that can be adapted to a wide variety of different types to charge batteries fast. The key considerations that are best suited to meeting the challenges of fast charging systems. To make a device charge faster, either boost the amperage or vary the voltage in order to increase the amount of potential energy going to a device. This paper addresses the design of a new DC Fast Charge controller for EVs by using microcontroller based dc-dc converter, which provides both option either boost current or vary voltage. The proposed solution decreases the charging time of EVs and facilitates the integration of fast chargers in existing battery charging method.
\end{abstract}

\section{Keywords}

DC fast charging, dc-dc converter, Microcontroller.

\section{INTRODUCTION}

In modern days, the large-scale electrification of the transport sector has become a major field of research. The concept of the DC fast charge controller is needed in terms of exploring possible solutions to manage and control the integration of several electric vehicles (EVs) in sustainable cities, especially for a long-distance travel is concerned [1]. There are many factors are contributing to the spread of electric transportation such as the high levels of motor vehicle pollution in many cities. In addition, the costs of electrical batteries are dropping to affordable levels with better lifetimes and reliability [2]. Nevertheless, one main reason that prevents part of the new potential customers waiting period for EVs is the longer charging time as compared to gas fueled vehicles. So far, the fast battery charger has met implementation difficulties in the major urban \& suburban cities, because its progress poses demanding requirements in terms of EV [3]. Currently, the delivered power is between $7 \mathrm{~kW}$ and $43 \mathrm{~kW}$ in AC for public charging stations [4]. Approximate charging rate requires about 1 hour or 2 hours to store the energy needed for battery charging process so as to cover $110 \mathrm{~km}$ to $150 \mathrm{~km}$. To identify this issue, a research is moving in various directions. However, this solution still brings along concerns about batteries to fast charging (FC) is to decrease the charging process time with a dedicated electronic circuitry.

To understand the fast battery charging the output of a charge is measured in amperage and voltage. Amperage (or current) is the amount of electricity flowing through the battery to the connected device, while voltage is the strength of the electric current. By multiplying voltage and current gives you wattage, the measure of total power in watts. Now a days Lithium ion (Li-ion) batteries are considered to be the standard for modern battery electric vehicles. There are various types of $\mathrm{Li}$-ion batteries that each has different characteristics, but vehicle manufactures are focused variants that have excellent longevity. Compared to other mature battery technologies, Li-ion batteries offer many benefits. For example, it has excellent specific energy and energy density, making it ideal for battery electric vehicles [5].

\section{BATTERY CHARGING METHODS[7]}

Various methods used to charge batteries. Methods are constant-current method, constant-voltage method, modified constant-voltage method, float charging method, and trickle charging method.

\subsection{Constant Current Charging Method}

In Constant-current charging method, available current is applied to battery for a certain to recharge it. This is set a low (usually less than $0.1 \mathrm{C}$ ) to avoid the voltage across the battery. i.e. from exceeding the gassing voltage as the battery charge approaches $100 \%$. This method is used for charging some small lead-acid batteries; it is not widely used for leadacid batteries, because their risk of generation of gassing is more when charging a battery partially discharged [7].

\subsection{Constant Voltage Charging Method}

In the constant-voltage charging method, a fixed pre-settable voltage is applied to the battery to recharge it. But use of this method initial charging current is very high and can even reach higher values as current prescribed by the battery manufacturer [7].

\subsection{Modified Constant Voltage Charging Method}

In the modified constant-voltage charging method, both a constant initial current and a constant finishing charge rate are used. Battery charging process starts with a constant current up to a certain voltage is reached (i.e. gassing voltage). And battery continues with a constant-voltage charging just equal to or slightly below the gassing voltage until the current decreases to a value of about. At this point, the constantvoltage is reduced to the float value to complete and maintain the battery charge. Figure 1 shows the charging characteristic curves for modified constant-voltage charging method. This charging method called as the fast charging method [7]

\subsection{Float Charging Method}

In the float charging method, a constant voltage, set to a value just sufficient to charge full battery. Typical voltage level is about $2.15 \mathrm{~V}$ to $2.3 \mathrm{~V}$ per battery cell [7].

\subsection{Trickle Charging Method}

In the trickle charging method, a low-level constant current is applied to the battery. This small current is sufficient to maintain the full charge of a battery [7]. 


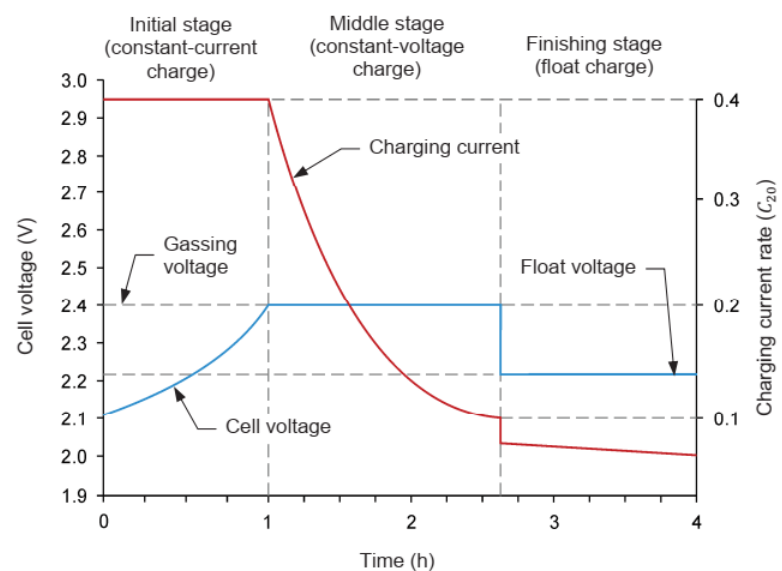

Fig. 1 Modified Constant Voltage Charging Method [7]

\section{RESEARCH PROBLEM}

There are many factors are contributing to the spread of electric transportation such as the high levels of motor vehicle pollution in many cities. Nevertheless, one main reason that prevents part of the new potential customers waiting period for EVs is the longer charging time as compared to gas fueled vehicles. So far, the fast battery charger has met implementation difficulties in the major urban \& suburban cities, approximate charging rate requires about 1 hour or 2 hours to store the energy needed for battery charging process so as to cover $110 \mathrm{~km}$ to $150 \mathrm{~km}$. Normally in electrical vehicles uses Lead Acid, Nickel-Cadmium (Ni-Cd) and Lithium-Ion (Li-Ion) batteries, to charge this battery usually setup up a charging pump but they are into two general categories: Fast charge is typically a system that can recharge a battery in about one or two hours, while slow charge usually refers to an overnight recharge (or longer).

\section{PROPOSED TECHNIQUE}

Here proposed a project on rapidly charging of battery using dynamic method. Battery is one of the nonlinear and there is no problem with fast charging an empty Li-ion up to about $50 \%$ state-of-charge (SoC). Applying a fast charging when the battery is empty and then narrowing off the current when reaching 50\% SoC and higher is called step charging. This dynamic charging method implemented by use of microcontroller with boost converter as shown circuit diagram of Fig.2. This circuit is build and tested by using Proteus 7.7 SP2 simulation software. The proposed fast charger uses Arduino Uno ATmega328 based microcontroller for generation of variable PWM pulses based on dynamic charging method as shown interfacing diagram Fig.2. These pulses are applied to boost converter so as to charge the battery in minimum time this is proved in table 1.

Arduino is an open-source platform used proposed fast charge controller. Arduino consists of both a physical programmable circuit board and a piece of IDE 1.6 software. Arduino is a separate piece of hardware and IDE uses a simplified version of $\mathrm{C}++$, making it easier to learn to program. Finally, Arduino provides a standard form factor that breaks out the functions of the micro-controller into a more accessible package [6].

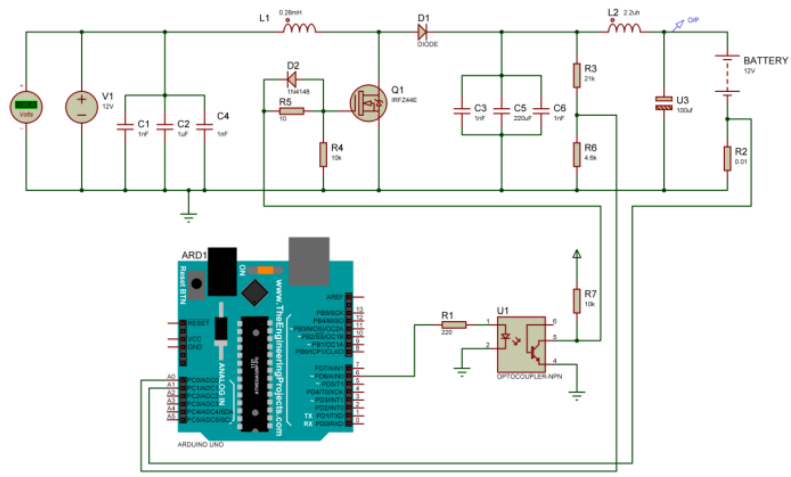

Fig 2. Circuit Diagram of Fast Charger

\section{RESULTS}

For testing of proposed fast charger select $12 \mathrm{~V}, 5 \mathrm{Amp}$ battery with initially fully discharged. When connecting a fast charger to discharged battery then initial battery charges with high current as 1.2 amps and this mode of charging called as fast mode. Whenever battery reaches to its above $60 \%$ battery rating then system goes into float charging mode. Hence battery The Fig $3 \&$ Fig. 4 shows the initial charging current and gate Mosfet gate pluses. Also the table 1 shows the charging process.

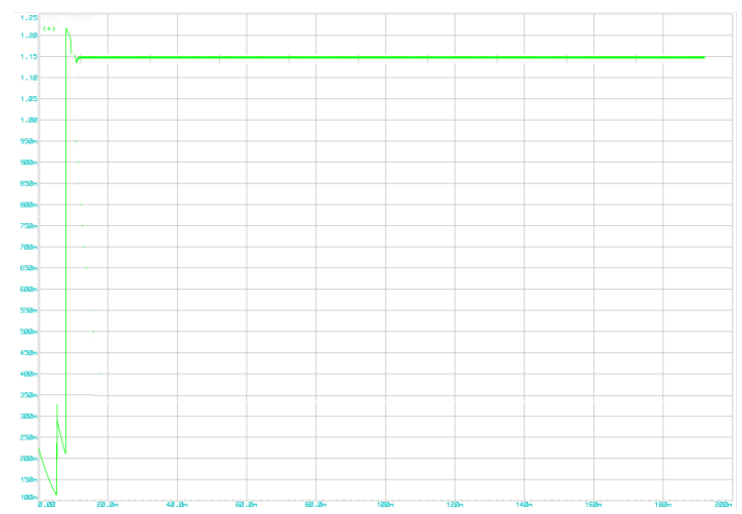

Fig.3 Battery charging current characteristics

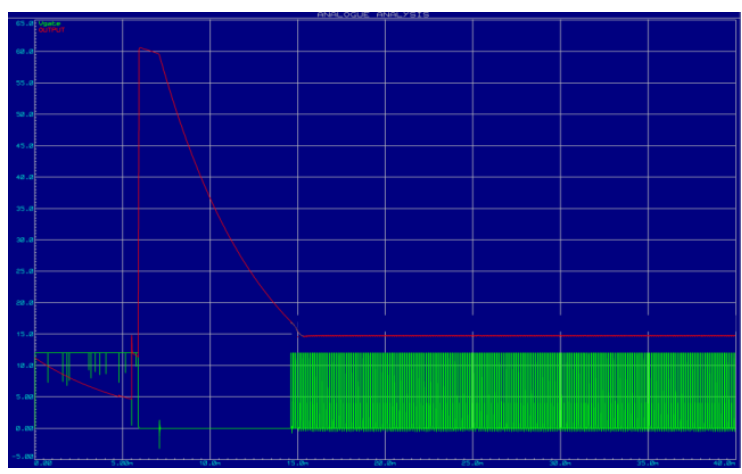

Fig 4 Output Voltage \& Mosfet Gate pluses waveforms

Table 1: Battery Charging Time

\begin{tabular}{|c|c|c|c|}
\hline $\begin{array}{l}\text { S.r. } \\
\text { No }\end{array}$ & $\begin{array}{c}\text { Battery } \\
\text { Voltage in } \\
\text { Volts }\end{array}$ & $\begin{array}{c}\text { Output } \\
\text { Current in } \\
\text { Amps }\end{array}$ & $\begin{array}{c}\text { Charging } \\
\text { Time in } \\
\text { minute }\end{array}$ \\
\hline 1 & 10.2 & 1.25 & 0 \\
\hline 2 & 10.5 & 1.2 & 5 \\
\hline
\end{tabular}




\begin{tabular}{|c|c|c|c|}
\hline 4 & 10.8 & 1.2 & 10 \\
\hline 5 & 11 & 1.2 & 15 \\
\hline 6 & 11.5 & 1.2 & 20 \\
\hline 7 & 11.8 & 1.2 & 25 \\
\hline 8 & 12 & 0.5 & 30 \\
\hline 9 & 12.5 & 0.3 & 35 \\
\hline 10 & 13 & 0.25 & 40 \\
\hline 11 & 13.2 & 0.18 & 50 \\
\hline
\end{tabular}

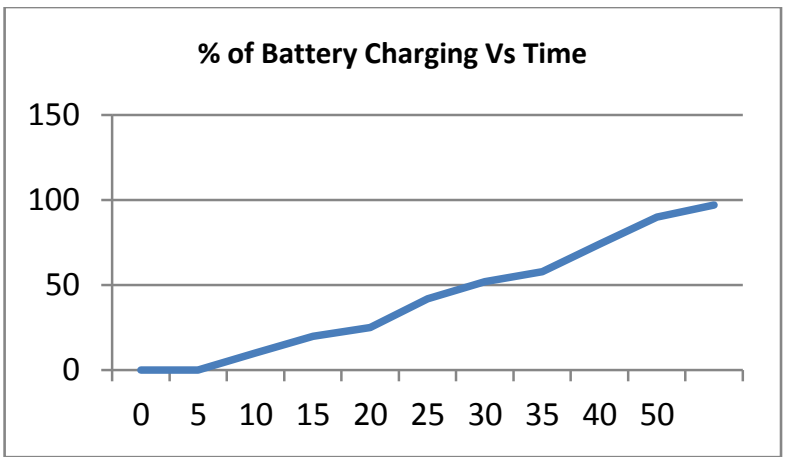

Fig. 7 Percentage of Battery Charging wrt. of Time

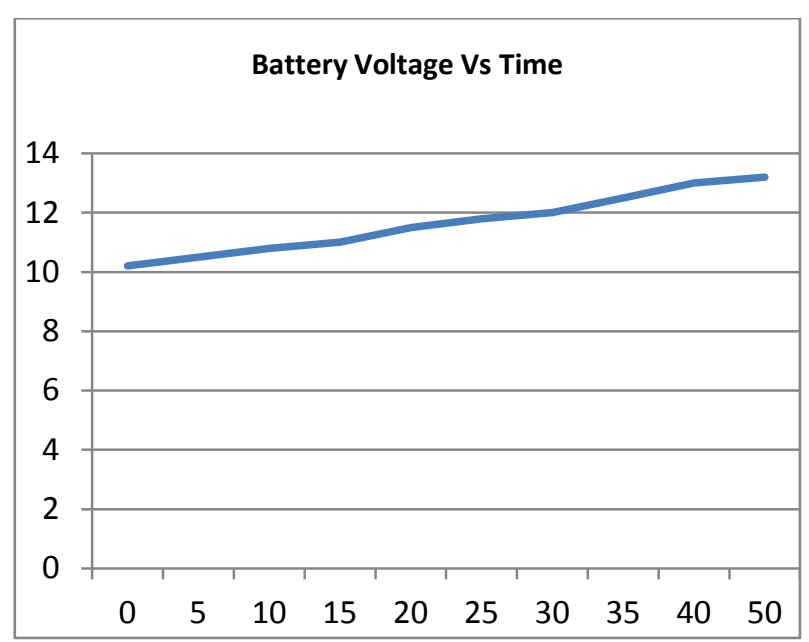

\section{CONCLUSION}

This paper proposes a dynamic charging method within the Boost dc-dc converter for fast battery charging purpose. The main objective is to charge EV battery in minimum time. The was conducted for $12 \mathrm{~V}, 5 \mathrm{Amp}$ battery and the table \& shows that the battery will be charged in within $50 \mathrm{~min}$. i.e. during initial charging battery charges in to boosting current mode and whenever battery charges to its $60 \%$ system goes into float charging mode so the resultant shows from table $1 \&$ fig. $3,5,6,7$ that battery charges quickly.

\section{REFERENCES}

[1] Nordhavn project; Design - dimensioning of the energy infrastructure of future sustainable cities, http://www.energylabnordhavn.dk/

[2] Björn Nykvist1 and Måns Nilsson, "Rapidly falling costs of battery packs for electric vehicles" , DOI: 10.1038/NCLIMATE2564, 2015.

Fig 5.: Battery Voltage Vs Time

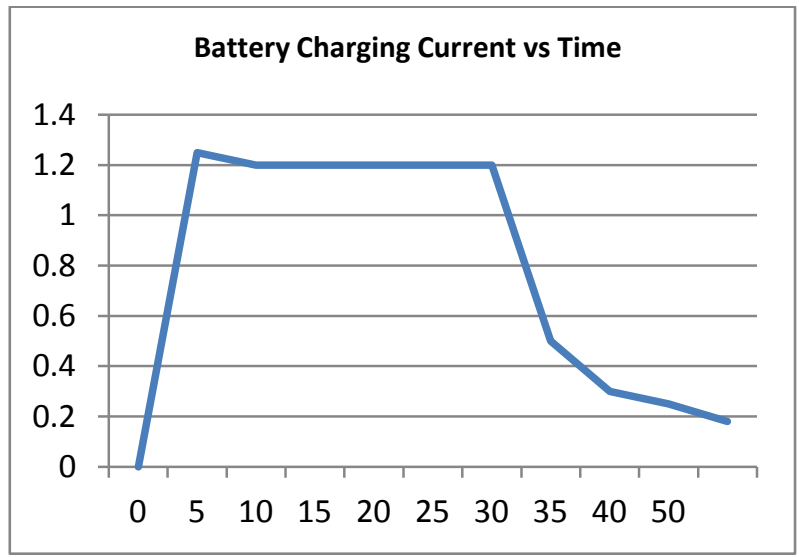

[3] Wen Chen and Chunlin Guo, "The Impact of fast charging for EVs on Distribution System", ISSN: 16628985, vols. 1070, pp 1664-1667

[4] IEC 61851: Conductive charging system / DC EV charging station

[5] A. F. Burke, "Batteries and Ultracapacitors for Electric, Hybrid, and Fuel Cell Vehicles," Proc. IEEE <95>, 606 (2007).

[6] https://www.arduino.cc/

[7] exercise 4 "Battery Charging methods" ( $)$ Festo Didactic 86351-00.

Fig. 6 : Battery Charging Current Vs Time 